\title{
STUDIES AND RESEARCHES CONCERNING POSSIBILITY OF INCREASING PRECISION AT SOWING MACHINES IN NESTS
}

\author{
Ion Saracin ${ }^{1}$, Mihnea Glodeanu ${ }^{1}$, Cristian Vasile ${ }^{1}$, Valentina Negulescu ${ }^{1}$, Olimpia Pandia ${ }^{2}$ \\ ${ }^{1}$ University of Craiova, Romania; ${ }^{2}$ USAMV Bucharest, Romania \\ ion_saracin@yahoo.com,mihneaglodeanu@yahoo.com,cristi_vasile_4you@yahoo.com, \\ negulescu_florenta@yahoo.com, olimpia_pandia@yahoo.com
}

\begin{abstract}
Precision sowing importance, as a factor influencing the development of crops determined the specialists in the field to do sustained research to find ways to mechanize the sowing work with high precision, to ensure the number of plants per unit area, respectively, the necessary space for plant development. Increased precision of agricultural sowing machines has direct implications on the germination, emergence and development of plants. The paper presents researches on precision sowing machines, equipped with pneumatic distributors, these being the most used models, manufactured by foreign and Romanian companies. The purpose of the experimental research was: determining the influence of certain physical characteristics, as the seed form, MMB on sowing accuracy; establishing the way in which these characteristics influence the free fall speed of the seeds from the distribution apparatus to the ground, taking into consideration the possibility of increasing this parameter, in order to reduce the travel times of the distance to the ground; determining the floating speed of seeds from several crops, this being an important parameter, which influences the design and adjustments of the sowing machines. The laboratory tests were performed on a stand with fixed sowing body. The seed distribution disk was driven with rotational speeds, corresponding to the working conditions, without slipping. Within the experimental laboratory researches, measurements were made in order to determine the uniformity of distribution of seeds on the row. Following the tests performed, it was found that the values of this parameter falls within the requirements imposed for sowing hoeing plants. The experimental results allow the elaboration of useful recommendations for farmers using these technical equipments.
\end{abstract}

Keywords: precision sowing machines, floating speed, uniformity of distribution.

\section{Introduction}

Within the technologies for setting up crop crops, precision sowing occupies an important and sensitive place. This implies the simultaneous observance of several conditions, starting with the selection of seeds, the preparation of the germination bed on the day of sowing, and also the use of seeding machines that provide at the highest level qualitative indications of work imposed on this work, simultaneously with the accomplishment of labour productivity as competitive as possible. In this sense, the sowing machines have been permanently improved, so that the norms per hectare are strictly observed, the depth of incorporation of seeds is uniform, the rows are straight, with equal distances between them, the distances between seeds, in turn, meet the demands of agrotechnics, etc. In order for precision drilling machines to be able to meet these requirements as rigorously as possible, permanent improvements have been made.

Some companies, (Väderstad), have taken precision sowing to a very high level. The technology available allows the acquisition of new electronic systems in the future. The heart of the drill is a dosing system that works perfectly in almost any conditions. The dispenser is capable of impressive accuracy even at high travel speeds, combined with low sensitivities to vibration and slopes. The secret behind these capabilities lies in the fact that the seeds are controlled from the moment they leave the dispenser and down to the ground. This function is called PowerShoot. Rapid transport decreases the effect of vibrations and slopes, thus maintaining accuracy to a very high value.

In the seeding machines provided with a pneumatic distribution device, a fan - exhaust fan is provided in the machine composition. The role of this fan - exhaust fan is to absorb the air from the depression chambers of the distribution devices, to reduce the pressure in these chambers in order to aspirate the seeds from the feed chamber, to stick them on the disc with holes, to keep the seeds glued to the disc until the moment of free fall through the coulter of the respective sowing section in the soil. The immediate benefit is the reduction of costs with the seed per hectare and the provision of nutrition space for plants. 


\section{Methods and equipment}

The research methodology regarding the precision sowing machines used in sowing the crops, subject to laboratory experiments, presents the way of conducting the research carried out, analyzing and interpreting the data on precision sowing according to the specialized literature. The machines that can be searched, respectively the type of the distribution device, the tractor with which the sowing unit forms, the working time, the speed of movement of the sowing unit with the power socket actuated by the variation of the speed of the collection band, were established. For seeds it was taken into account:

- forces acting on solid particles in an air stream;

According to the literature on a solid particle in an upward vertical air stream, a number of forces act [1-3].

- mass forces that are proportional to the particle mass;

- surface forces which modulus is proportional to the size of the particle surface.

The main mass forces are [3-5]:

- force of weight $G$;

- Archimedean force $A$;

- inertia force $F i$.

The surface forces are:

- dynamic forward pressure force $F d$;

- force of resistance to advancing $F R$;

- load force $F p$;

- Magnus force $F M$.

MMB (mass of thousand grains) floating solid particle in the air stream: the equation of motion of the solid particle in an upward vertical air stream, according to Figure 1 and 2, is presented by equation (1) [6-12]:

$$
m \frac{d v}{d t}=G-F_{i}-A
$$

where $m \frac{d v}{d t}-$ the force of inertia.
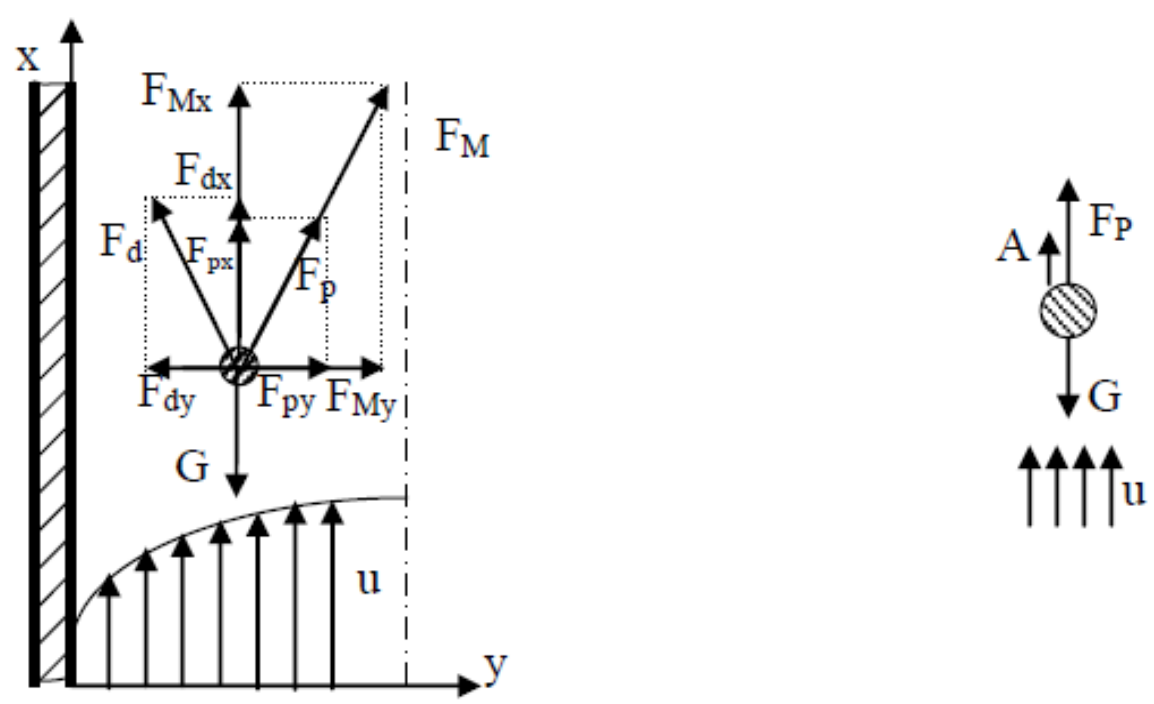

Fig. 1. Forces acting on stream [13]:

$G$ - particle own weight, $N ; F R$ - resisting force opposed by the air current, $N$;
Fig. 2. Forces acting on a particle in an air stream particle in a rising air: $A$ - force of Archimedes, equal to the mass of the volume displaced by the particle, $N$

For a particle suspended in the air stream, in case $v=0$, the equation is: 


$$
u=v P G=F R
$$

\section{Determination of the floating speed}

Since the section of the air channel corresponding to the laboratory stand used to determine this parameter is $50 \times 50 \mathrm{~mm}$, the value of the floating speed is determined analytically using the following calculation relation $[6 ; 7 ; 12]$ :

$$
V_{P}=\sqrt{\frac{4 d e \rho p g}{3 k \phi \gamma a}},
$$

where $d e$-diameter, $\mathrm{mm}$

$\rho p$ - solid particle density, $\mathrm{kg} \cdot \mathrm{m}^{-3}$;

$g$ - gravitational acceleration, $\mathrm{m} \cdot \mathrm{s}^{-2}$

$k$ - aerodynamic coefficient of resistance depending on the shape and condition of the surface;

$\gamma a-$ air density, $\mathrm{kg} \cdot \mathrm{m}^{-3}$

$\phi s$ - sphericity coefficient.

Magnus force values were not determined, because it acts on particles in an upward vertical air stream.

\section{Equipment and materials used}

- SPC seed drill 6 (8)

- Sowing unit test stand

- Types of seeds used in tests:

- Corn, variety FUNDULEA 475M, with MMB = 292-300 grams.

- Soybean, ATLAS, with MMB = 150-200 grams.

- Sunflower, FAVORITE variety, with MMB = 65-70 grams.

- Beans VERDANA variety, with MMB $=420-450$ grams.

According to the specialized literature, the seeds suitable for sowing are those with physical purity of over $98 \%$ and germination of over $85 \%$. At the same time, they must not have cracks, be uniform and with a mass of 1.000 grams (MMB).

The test stand is shown on Fig. 3.
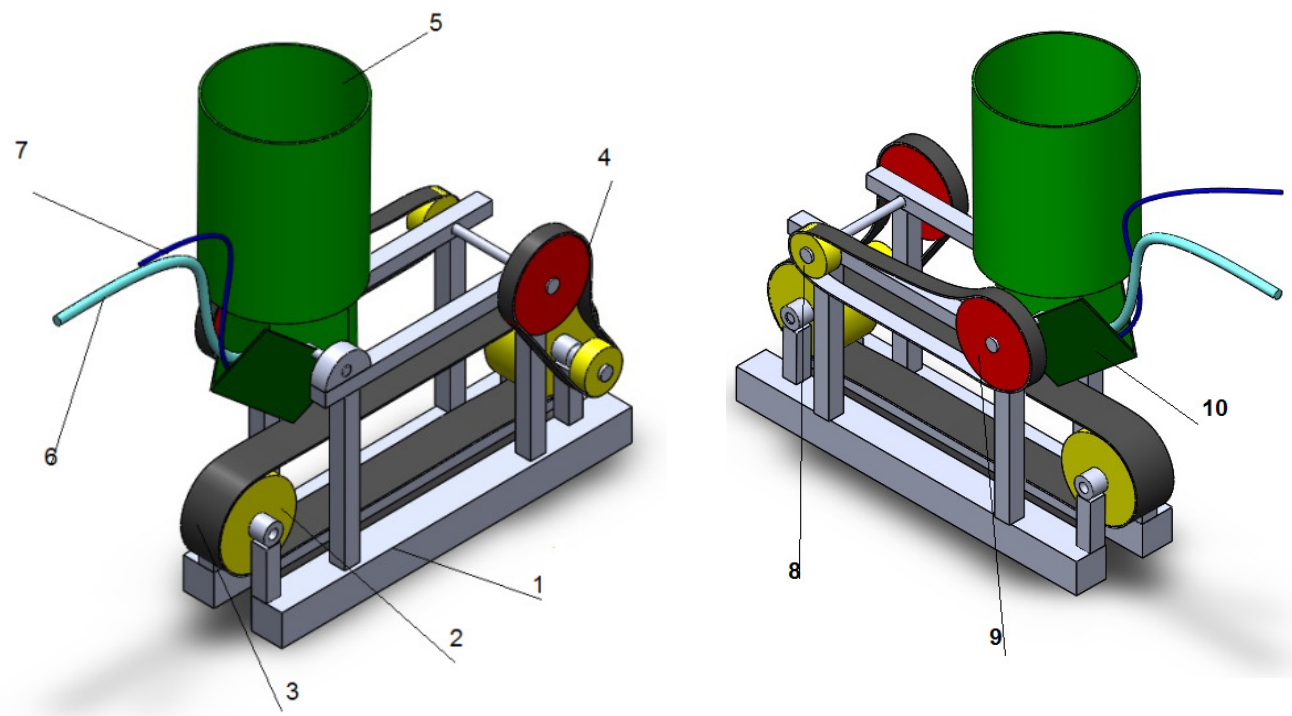

Fig. 3. Standard distribution device tests: 1 - frame; 2 - roller support; 3 - wide belt roller; 4 - drive wheel; 5 - seed box; 6 - depression hose; 7-pressure hose, 8 - wheel drive distribution device; 9 - wheel drive distribution device; 10 - coulter (Solid Works) 
The pneumatic distribution system with depression, modified shown in Figure 4 and 5, has the following components [14]:

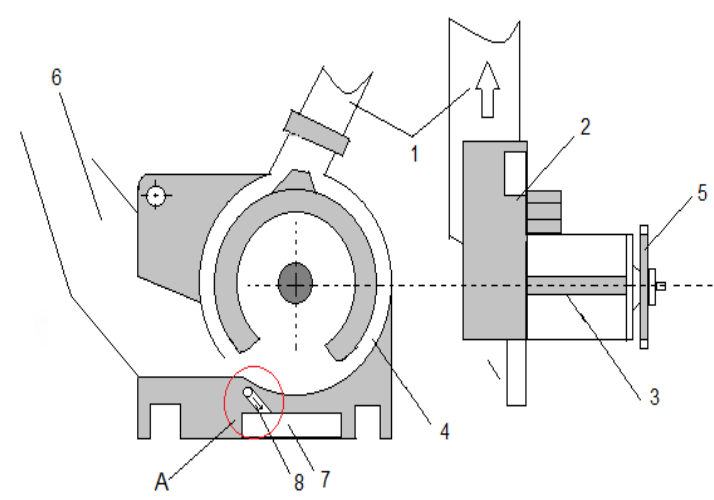

Fig. 4. Modified distribution device: 1 - suction chamber; 2 - depression chamber; 3 - drive shaft;

4 - disc with holes; 5 - gear; 6 - seed supply chamber; 7 - seed release room

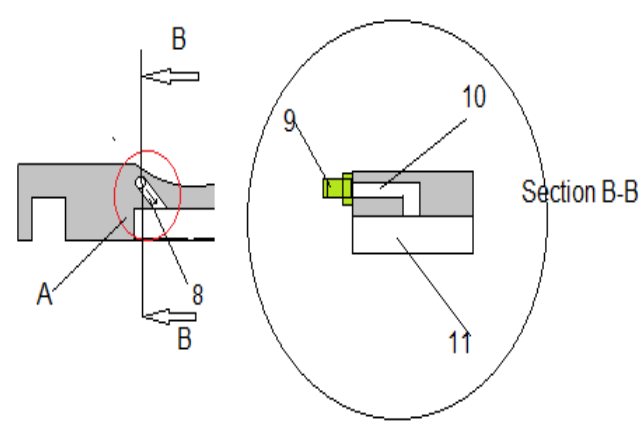

Fig. 5. Realization of the pressure channel in the seed evacuation chamber: 8 - air channel; 9 - pressure hose manifold; 10 - pressurized air duct; 11 - pressure seed release chamber

Air distributor is mounted on the fan body, it receives air from the exhaust fan outlet and can distribute it according to the needs through a hose with a diameter of $2 \mathrm{~mm}$, or $4 \mathrm{~mm}$, or $6 \mathrm{~mm}$, or 8 $\mathrm{mm}$ to the distribution devices with depression and disc with holes (Fig. 6).

The user uses the valve in connection with the outlet chamber of the distributor and adjusts the air velocity in the exhaust chamber according to the type of seeds.

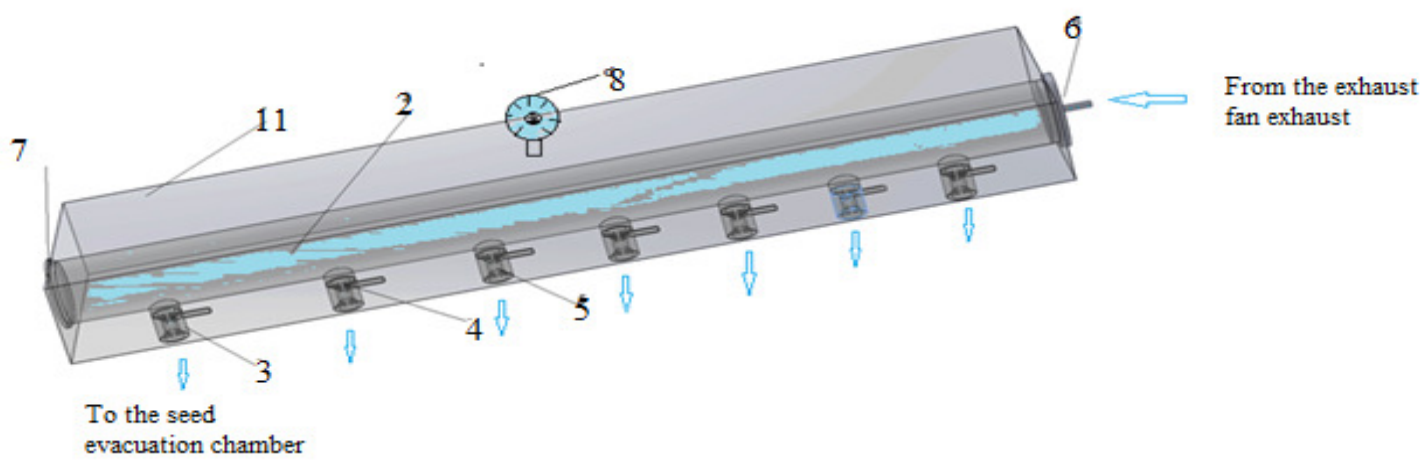

Fig. 6. Air distributor: 1 - distributor body; 2 - channel pressure air; 3 - air valve; 4 - channel pressure air; 5 - pressure tube connection socket; 6 - link outlet mouth exhaust fan; 7 - technological stopper; 8 - manometer (Solid Works)

\section{Results}

Test preparation: the weight of each seed to be studied was calculated, Table 1. From the specialized literature, the sphericality coefficient and the floating speed were taken into account, according to Table 1.

Table 1

Floating speed of the seeds studied

\begin{tabular}{|c|c|c|c|}
\hline $\begin{array}{c}\text { Seed } \\
\text { type }\end{array}$ & $\begin{array}{c}\text { Sphericity } \\
\text { coefficient }\end{array}$ & $\begin{array}{c}\text { Floating speed, } \\
\mathbf{m} \cdot \mathbf{s}^{-\mathbf{1}}\end{array}$ & $\begin{array}{c}\text { Weight of seed, } \\
\mathbf{g}\end{array}$ \\
\hline Corn & 0.90811 & 3.300 & $0.292-0.300$ \\
\hline Soy & 0.94323 & 4.315 & $0.150-0.200$ \\
\hline Sunflower & 0.82965 & 3.512 & $0.065-0.070$ \\
\hline Beans & 0.88132 & 3.821 & $420.0-450.0$ \\
\hline
\end{tabular}


The exhaust fan was connected to the tractor power outlet for $540 \mathrm{rpm}$. Depression in the depression chamber of the distributor on the test stand was measured, 0.6 bar.

The travel time of the distance between the distributor and the bottom of the open coulter channel was calculated under normal working conditions for each seed type.

$$
V=D / T, \mathrm{~ms}^{-1}
$$

where $D$ - distance between the distributor and the bottom of the open coulter, m;

$T$ - travel time, s.

Thus for the distance of $15 \mathrm{~cm}$, respectively the height of fall was:

- for maize, $T=0.0454, \mathrm{~s}$

- for soybean, $T=0.0347, \mathrm{~s}$

- for sunflower, $T=0.0427, \mathrm{~s}$

- for beans, $T=0.0392, \mathrm{~s}$.

For other speeds of air flow in the exhaust chamber, provided by the exhaust fan through the air distributor, the travel speeds of the distance of 0.15 meters, at a speed of $1.6 \mathrm{~m} \cdot \mathrm{s}^{-1}$ are presented in a Table 2.

Table 2

Seed displacement speed and uniformity of distribution

\begin{tabular}{|c|c|c|c|c|c|c|}
\hline Seed type & $\begin{array}{l}\text { Diameter } \\
\text { of the air } \\
\text { tube, } \mathrm{mm}\end{array}$ & $\begin{array}{l}\text { Travel } \\
\text { time, } s\end{array}$ & $\begin{array}{c}\text { Air } \\
\text { velocity in } \\
\text { the tube, } \\
\mathrm{m} \cdot \mathrm{s}^{-1}\end{array}$ & $\begin{array}{c}\text { Traveled } \\
\text { distance, } \\
\text { m }\end{array}$ & $\begin{array}{l}\text { Distance } \\
\text { between } \\
\text { seeds, m }\end{array}$ & $\begin{array}{c}\text { Uniformity of } \\
\text { distribution, } \\
\%\end{array}$ \\
\hline \multirow{4}{*}{ Corn } & 2 & 0.0414 & 0.61 & \multirow{4}{*}{0.15} & \multirow{4}{*}{0.28} & 96.0 \\
\hline & 4 & 0.0392 & 0.82 & & & 97.5 \\
\hline & 6 & 0.0361 & 0.96 & & & 98.0 \\
\hline & 8 & 0.0318 & 1.10 & & & 98.6 \\
\hline \multirow{4}{*}{ Soy } & 2 & 0.0307 & 0.61 & \multirow{4}{*}{0.15} & \multirow{4}{*}{0.28} & 96.2 \\
\hline & 4 & 0.0286 & 0.82 & & & 97.1 \\
\hline & 6 & 0.0257 & 0.96 & & & 98.2 \\
\hline & 8 & 0.0234 & 1.10 & & & 98.8 \\
\hline \multirow{4}{*}{ Sunflowers } & 2 & 0.0397 & 0.61 & \multirow{4}{*}{0.15} & \multirow{4}{*}{0.28} & 96.0 \\
\hline & 4 & 0.0375 & 0.82 & & & 96.4 \\
\hline & 6 & 0.0347 & 0.96 & & & 97.5 \\
\hline & 8 & 0.0326 & 1.10 & & & 98.7 \\
\hline \multirow{4}{*}{ Beans } & 2 & 0.0372 & 0.61 & \multirow{4}{*}{0.15} & \multirow{4}{*}{0.28} & 97.0 \\
\hline & 4 & 0.0341 & 0.82 & & & 97.3 \\
\hline & 6 & 0.0312 & 0.96 & & & 98.2 \\
\hline & 8 & 0.0296 & 1.10 & & & 99.1 \\
\hline
\end{tabular}

\section{Conclusions}

1. The value of the floating speed of a solid particle is inversely proportional to the value of the sphericity coefficient of the solid particle, regardless of the value of the density of the solid particle.

2. Depending on the diameter of the air transmission tube of the seed evacuation chamber, their fall time has changed.

3. The modification of the fall time led to the increase of the uniformity of seed distribution on the stand band.

4. It can be appreciated that for other tests other values of air velocity can be used in the air supply tube of the seed evacuation chamber, through actions on the valves of the air distributor.

5. The coefficient of sphericity in the case of the use of air stream does not significantly influence the parking time of the distance from the seed distribution apparatus to the ground. 


\section{References}

[1] Jefferey R.C., Pearson J.R.A. Particle motion in laminar vertical tube flow, Journal of Fluid Mechanics, August 1965, Volume 22, Issue 04, pp. 721-735.

[2] Hilton J.E., Cleary P.W. The role of particle shape in pneumatic conveying, Seventh International Conference on CFD in the Minerals and Process Industries, CSIRO, Melbourne, Australia, 9-11 December 2009.

[3] Benny K., Schwarz P. Numerical Prediction of dilute flows in horizontal and vertical ducts, Third International Conference on CFD in the Mineral and Process Industries, CSIRO, Melbourne, Australia, 2003, pg. 135-140.

[4] Mortensen P.H., Andersson H.I., Gillissen J.J.J., Boersma B. J. Particle spin in a turbulent shear flow, Physics of fluids, 2007, vol. 19, issue 7.

[5] Seyun K., Lee K.B., Lee C.G. Theoretical approach on the turbulence intensity of the carrier in dilute two-phase flows, International communications in heat and mass transfer, 2005, vol. 32, nr. 3-4, pp. 435-444.

[6] Housner G.W., Hudson D.E. Applied mechanics dynamics, Division of Engineering California Institute of Technology, 1980, $399 \mathrm{p}$.

[7] Huang P.Y., Feng J., Hu H.H., Joseph D.D., Direct simulation of the motion of solid particles in Couette and Poiseuille flows of viscoelastic fluids, J. Fluid Mech., 1997, vol. 343, pp. 73-94.

[8] Syusaku H., Toshitsuguşi T., Yutaka T. Fluid force acting on a falling particle toward a plane wall, Proceedings ASME FEDSM'00, Fluids Engineering Division Summer Meeting, Boston, Massachusetts, June 11-15, 2000.

[9] Csizmazia Z., Polyak N.I. Movement of Particles in the Air, University of Debrecen, Centre of Agricultural Sciences, Debrecen, 2001, pp. 1-5. [online][11.02.2020] Available at: http://www.date.hu/actaagraria/2001-01i/csizmazia.pdf; 64

[10] Iliescu L. and other, Procese şi utilaje în industria alimentară (Processes and machines in the food industry) E.D.P., Bucureşti, 1978, 183 p. (In Romanian)

[11] Akira Ogawa. Separation of particles from air and gases, CRC Press, Inc. Boca Raton, Florida, 1987, vol. I., 152 p.

[12] Căproiu Șt., ScripnicV., et.al. Mașini agricole de lucrat solul și semănat (Agricultural machines for tillage and sowing) Ed. Did. Ped.Bucharest 1982. 473 p. (In Romanian) 